\title{
CAN THE PRINCIPLE OF SELF-ORGANIZED GRADIENTS BE APPLIED FOR HUMAN SYSTEMS? A CASE STUDY ON RURAL-URBAN INTERACTIONS
}

\author{
FRANZISKA KROLL \& FELIX MÜLLER \\ Institute for the Conservation of Natural Resources, Christian-Albrechts University of Kiel, Germany.
}

\begin{abstract}
The ecological gradient approach states that self-organized processes produce patterns of concentration profiles that can be distinguished into structural and functional gradients. Throughout the undisturbed development of such systems, certain attributes are regularly optimized. These 'orientors' can be used to characterize the state of open systems. H. Bossel has introduced a set of 'basic orientors', which can be applied as indicators and target functions of any self-organized system. In this paper we combine the gradient approach with the basic orientor concept to test if the principles of self-organization can also be used to describe human entities. The case studies utilized are representing several concentration profiles between urban and rural landscapes in Europe. These spatial gradients, which have been arising from long-term development of cities and their hinterlands, are assigned to the basic orientors' existence, effectiveness, freedom of action, security, adaptability, and coexistence. The results show that in all cases the demanded patterns can be found, thus there are functional parallels between self-organizing processes in ecological and human systems. The basic orientor approach can be used to explain these patterns, i.e. to clarify the utility of the outcome of self-organized processes in nature and society. Keywords: self-organizing systems, basic orientors, ecological gradients, rural-urban gradient, urbanization.
\end{abstract}

\section{INTRODUCTION}

Whenever spatial differences in the concentrations of functional and structural variables appear, the resulting patterns can be aggregated to gradients. As Müller and Kroll [1] have discussed in this issue, such gradients are typical outcomes of self-organized processes. Therefore, gradients are suitable instruments to describe ecological structures, to understand ecological functions, and to analyze environmental patterns. With this paper we want to test if such self-organized features and patterns can also be found in human-environmental or social systems.

\subsection{Self-organization in ecological and human-environmental systems}

Ecosystems are open and complex systems that are driven by inputs of exergy, matter, and information and outputs of degraded forms of energy [2]. Under this precondition of continuous exchange with the environment, ecosystems are self-organizing systems that form ordered, dissipative structures [3-8]. Thereby, they move away from thermodynamic equilibrium, but increase the entropy outside the system, following the second law of thermodynamics. According to orientor theory $[9,10]$, the formation of ordered structures in line with the undisturbed self-organization process of ecosystems follows the dynamics of so-called orientors, which describe the resulting direction of ecosystem development [2]. They can be distinguished into thermodynamic orientors, information theoretical orientors, structural and community orientors, and network theoretical orientors [1]. All have in common the fact that the complexity and connectivity of ecosystems and their elements is maximized along the pathway of orientor development. Although the mature ecosystems with increased complexity and connectivity show many aspired characteristics such as high energetic efficiency and structural heterogeneity, they exhibit a low adaptability and therefore have a high risk to fail recovery after an external disturbance [11].

(C) 2011 WIT Press, www.witpress.com

ISSN: 1755-7437 (paper format), ISSN: 1755-7445 (online), http://journals.witpress.com

DOI: 10.2495/DNE-V6-N4-342-360 
Another consequence of dissipative self-organization is the formation of internal structural, functional, and temporal gradients that indicate the system's distance from thermodynamic equilibrium $[1,2,12]$. These gradients build up potentials and evoke flows of energy, matter, and information within the ecosystem; thus they are the driving forces of all ecological processes and can be used to indicate a system's self-organising capacity [12].

The concepts of self-organization and dissipative structures have not only been applied in ecological research, but are also widely discussed in geography and social science, especially in relation with cities and urbanization [8,9,13-17]. Also urban systems are complex, open systems that import energy, matter, and information from their regional and global hinterlands and export degraded energy in form of gaseous, liquid, and solid wastes. This exchange enables the urban system to create complex, ordered structures and minimize the entropy level within the system $[8,18]$. Consequently, while the urban system itself is getting more and more complex, the hinterland has to cope with increasing entropy levels.

As an emergent property of self-organizing systems, human systems are also assumed to follow orientor dynamics $[19,20]$. According to Bossel [9], basic orientors in social systems are values and norms, objectives and goals that direct the behavior and the development of the system and have emerged in response to general environmental properties and challenges. Bossel [9] lists six basic orientors that, as he states, are common to all agents in self-organizing systems and represent the system agents' fundamental interests, namely the orientors existence, effectiveness, freedom of action, security, adaptability, and coexistence (see Table 1 for definitions). While these system features must be seen as resulting properties of ecosystem evolution and self-organization in the environmental cases (which do not follow any target), in human system teleological arguments must not be avoided: humans define objectives and therefore they can consciously manage their environment looking for optimized steady states, e.g. by fulfilling the demands of the basic orientors.

\subsection{Urbanization and self-organization}

Cities differ from rural areas in terms of population density, involvement in agriculture, labor division, and concentration of political power and administration, to name a few. However, there is no universally valid definition of the distinction between rural and urban areas due to different classifications of both area types from one country to the other [21]. An analysis of long-term developmental trends might therefore be helpful.

The history of urbanization is closely linked to the Neolithic revolution and begins in $4^{\text {th }}$ millennium B.C. in Mesopotamia, representing an essential landmark in human evolution [22]. Mumford [23] names the improvement in food production that made it possible to support a bigger population not involved in agriculture and the consequential surplus of manpower that could be used for other forms of work and services as main preconditions for the emergence of cities. As the earliest cities depended on the resource supply of their rural hinterlands, they evolved near to fertile agricultural land and water sources and their growth was limited by the carrying capacity of their direct hinterlands. Progress in transport that allowed for imports and exports over large distances is seen as one main driving factor of the second stage of accelerating urbanization that took place in parallel to the industrial revolution in developed countries [21]. Food, water, and energy supply, transportation and fortification were no limits for the growth of cities any longer [23]. Marti-Henneberg [24] presents empirical evidence that Europe's population has undergone progressive concentration and has clumped more and more in densely populated areas from the end of the $19^{\text {th }}$ century until today. Today, more than half of the global population is living in cities 
Table 1: Definitions of six basic orientors after Bossel [9].

\begin{tabular}{|c|c|c|}
\hline $\begin{array}{l}\text { Basic } \\
\text { orientors }\end{array}$ & $\begin{array}{c}\text { Definitions } \\
\text { ([9], pp. 341-342) }\end{array}$ & $\begin{array}{c}\text { Exemplary respective ecosystem } \\
\text { features }\end{array}$ \\
\hline Existence & $\begin{array}{l}\text { "The system must be compatible with, } \\
\text { and able to exist in the normal } \\
\text { environmental state. The information, } \\
\text { energy, and material inputs necessary to } \\
\text { sustain the system must be available." }\end{array}$ & $\begin{array}{l}\text { Maintaining steady state dynamics } \\
\text { and self-regulation via resilience } \\
\text { and adaptability; enhancing } \\
\text { resource availability. } \\
\text { (e.g. radiation, water, nutrients) }\end{array}$ \\
\hline Effectiveness & $\begin{array}{l}\text { "The system should on balance be } \\
\text { effective in its efforts to secure scarce } \\
\text { resources from, and to exert influence } \\
\text { on its environment." }\end{array}$ & $\begin{array}{l}\text { Cycling processes, stepwise gradient } \\
\text { degradation, storage processes, and } \\
\text { mutual adaptation. }\end{array}$ \\
\hline $\begin{array}{l}\text { Freedom of } \\
\text { action }\end{array}$ & $\begin{array}{l}\text { "The system must have the ability to } \\
\text { cope in various ways with the challenges } \\
\text { posed by environmental variety." }\end{array}$ & $\begin{array}{l}\text { Functional redundancies and ontic } \\
\text { openness (see [7]). }\end{array}$ \\
\hline Security & $\begin{array}{l}\text { "The system must be able to protect it- } \\
\text { self from the detrimental effects of } \\
\text { environmental variability, i.e. variable, } \\
\text { fluctuating, and unpredictable } \\
\text { conditions outside of the normal } \\
\text { environmental state." }\end{array}$ & $\begin{array}{l}\text { Ecosystem properties that allow in- } \\
\text { creasing resilience, buffer capacity, } \\
\text { or adaptability } \\
\text { (storage compartments, tolerances } \\
\text { of species). }\end{array}$ \\
\hline Adaptability & $\begin{array}{l}\text { "The system should be able to learn, } \\
\text { adapt, and self-organize in order to } \\
\text { generate more appropriate responses to } \\
\text { challenges posed by environmental } \\
\text { change." }\end{array}$ & $\begin{array}{l}\text { Following the orientor pathways in } \\
\text { spite of disturbances and being able } \\
\text { to optimize functional orientors at } \\
\text { the long-term. }\end{array}$ \\
\hline Coexistence & $\begin{array}{l}\text { "The system must be able to modify its } \\
\text { behaviour to account for behaviour } \\
\text { and interests of other systems in its } \\
\text { environment." }\end{array}$ & $\begin{array}{l}\text { Openness for change and reactions } \\
\text { resulting from high-scale processes } \\
\text { and structures (e.g. transfer } \\
\text { processes at the landscape scale). }\end{array}$ \\
\hline
\end{tabular}

[25], whereas the fastest population growth is observable in the megacities of developing countries whose speed of population increase dwarfs the one that happened in European cities during the industrial revolution [26, 27].

However, the fulfilment of the necessary preconditions for the formation of cities alone does not explain their existence. Although the hypothesis exists that first cities "did not simply happen" but were intentionally created by a powerful elite ([28], p. 528), the more prevalent thesis is the interpretation of urbanization by using the theory of self-organization. Thereby, the self-organization of cities is seen as being triggered by population pressure [14]. It contrasts the static theories of central places being in an equilibrium state that were introduced by Lösch [29] and Christaller [30] by interpreting the landscape as a far-from equilibrium situation "in which the spatial hierarchical order among the central places is obtained, maintained and then transformed, by means of an interplay between interaction and fluctuations, on the one hand, and dissipation on the other" ([14], p. 360). 
In this paper, we aim at exploring if orientor theory can help explain the process of self-organizing urbanization. If urban systems develop in a self-organized manner along the pathway of orientor dynamics, this process should also evoke the formation of internal gradients that allow for a spontaneous flow of energy, matter, and information. The study of these gradients could help analyzing the state of the system, which is in this case the rural-urban region. Thus, in this paper, we aim at answering the following questions:

- Can basic orientors explain the existence of cities and the ongoing urbanization? Are orientor interests better met in cities? If so, is the human system heading to a state of maximum urbanization?

- According to the theory, human systems should build gradients as a consequence of self-organization. Is it thus possible to transfer the gradient concept to human systems?

The paper is organized as follows: in the first part, a short description of data acquisition and gradient calculations is given. Subsequently, the results of the calculations and their relations to the orientor theory are presented. In the last part, the results are discussed and some final conclusions are drawn.

\section{MATERIAL AND METHODS}

The first step of our analysis was the selection of suitable indicators for the representation of basic orientors in relation to urbanization. The chosen variables represent major indicators of sociodemographic (population density, medium age, hospital beds, foreign persons, personal computer users, internet users, literacy rate, life expectancy, human development index), economic (dwelling area, unemployment rate, employees, GDP per person, income per person), and environmental (sealed surface, urban fabric, food supply and demand) sustainability indicators that can also be linked to orientor theory. To put them into relation with urbanization, we also chose the urbanization rate as variable for analysis. The second step was the data collection for these indicators, which we conducted at two spatial scales to provide a sufficient breadth of analysis. On the one hand, we collected data at the local level of city districts and municipalities that served as the basis for the calculation of ruralurban gradients. Rural-urban gradients were calculated by linking the statistical and spatial data to shape files of the administrative units of the city regions in GIS ArcView 3.2 by ESRI. Subsequently, a series of concentric rings with a diameter of $1 \mathrm{~km}$ each was created around the city centers and medium indicator values for each ring distance were calculated. For a detailed description of gradient calculations, see Kroll and Kabisch [31] and Kroll et al. [32]. As case study regions, six major European cities being situated in three different countries were chosen: Berlin, Munich, Leipzig, Hamburg, Manchester, and Warsaw. These cities represent important European urban agglomerations, however with different locations, different historical backgrounds, and different urban forms.

On the other hand, data on the national level were used for the analysis of the general relationship between the urbanization rate and several social and economic indicators that represent the state of the nation according to orientor development. A correlation analysis with data of approximately 200 nations was conducted to calculate Pearson's correlation coefficients between the urbanization rate and the chosen social and economic indicators. Table 2 summarizes all indicators, scales, and data sources used for the analysis.

\section{RESULTS}

As mentioned above, basic orientors are seen as emergent properties of self-organizing systems. Expressed in form of rural-urban gradients, they are expected to help explaining the existence of cities. To test this hypothesis, we analyze the basic orientors introduced by Bossel [9] in relation to urbanization one by one. 


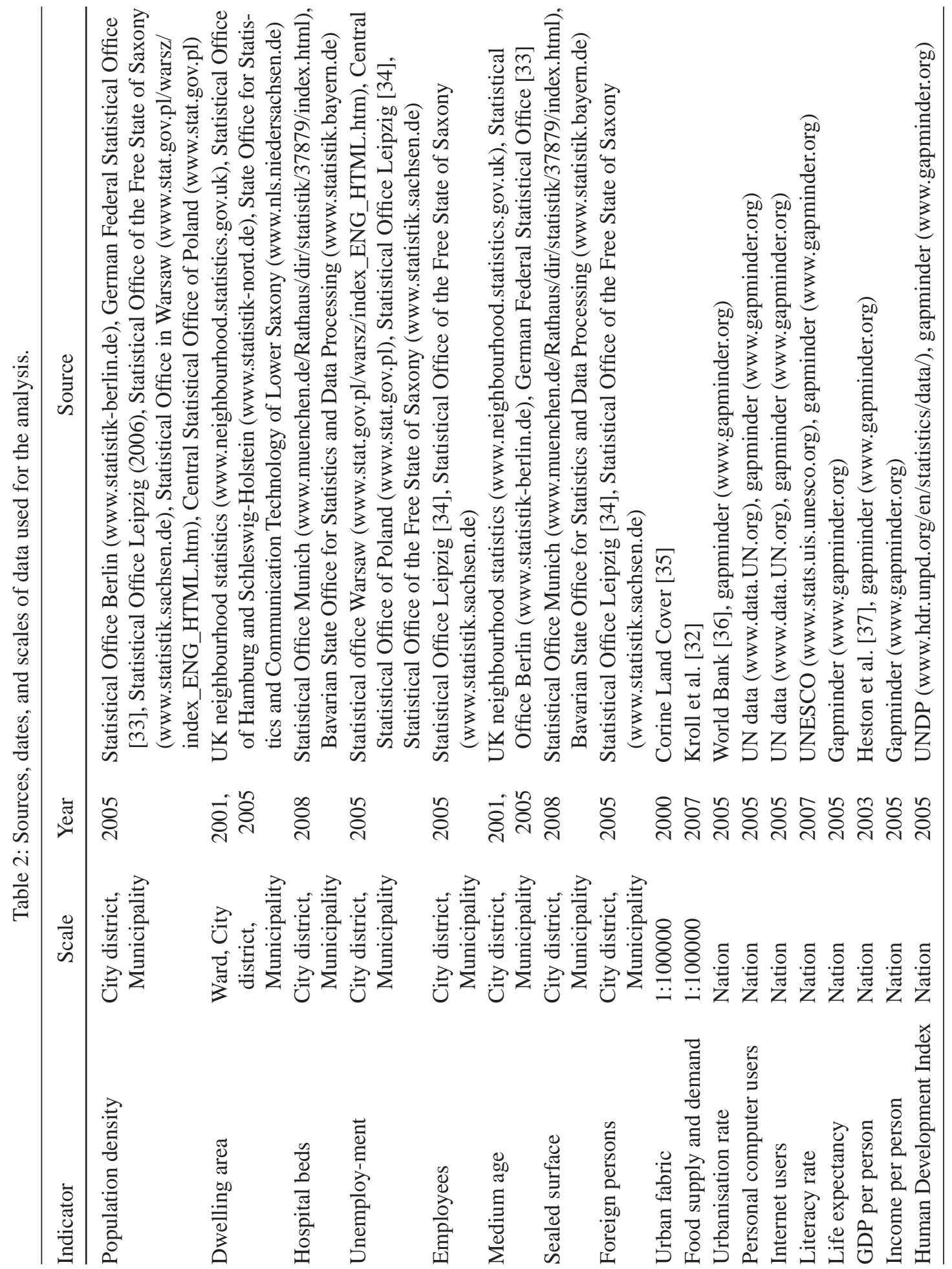


The first is the existence orientor. It describes the fundamental system interest to sustain and exist in compatibility with its environment [9]. In the case of urbanization, the existence orientor helps explaining why first cities were built near fertile soils, adequate water sources, and transport facilities and in favorable climatic conditions. These conditions guarantee the necessary inputs of energy, matter, and information to the urban system and thereby enhance the system's resilience as well as the one of the system agents, namely the people living in the city. They are also necessary to ensure the people's 'basic functions of existence' that have been introduced as a concept of social geography by Partzsch [38] and include the functions reproduction, habitation, working, feeding and consuming, education, recreation, and transport. The existence of cities can be illustrated in the form of rural-urban gradients, as cities differ in two fundamental spatial characteristics from their rural surroundings: population density and land use. An example of rural-urban gradients for both of these characteristics is given for the cities of Berlin, Leipzig, Warsaw, and Manchester (Figs. 1 and 2).

Not surprisingly, both variables decrease with the distance from the city center. The population density gradients (Fig. 1) have their maxima values at a small distance from the center in the case of Berlin and Leipzig. This phenomenon can be observed in many monocentric cities due to the 'competition' of residential areas with central business districts in inner city centers [31].

Bossel's effectiveness orientor describes the necessity for the system to be effective, meaning to minimize the use of scarce resources. Cities fulfil this requirement better than their rural counterparts due to concentrated flows of matter, energy, and information. Weisz and Steinberger [39] argue that an efficient urban form can significantly lower material and energy consumption. They found that urban areas are less resource intensive in terms of direct household energy consumption compared to rural settlements. Also the energy consumption for traffic decreases with increasing

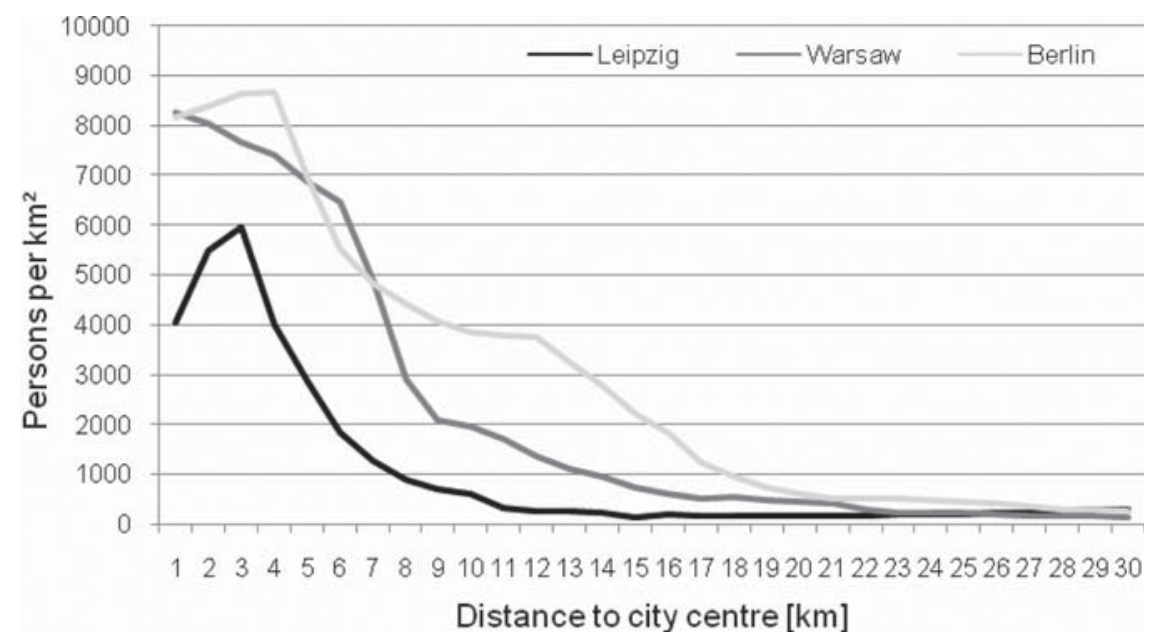

Figure 1: Rural-urban gradients of population density for the cities of Berlin, Warsaw and Leipzig in 2005. Each gradient curve point represents the average value of population density in a concentric ring with a $1 \mathrm{~km}$ diameter at the respective distance from the city centers. The lower population densities in the city centers of Leipzig and Berlin can be explained with the 'competition' with other land use types, e.g. central business districts. See Table 2 for data sources. 


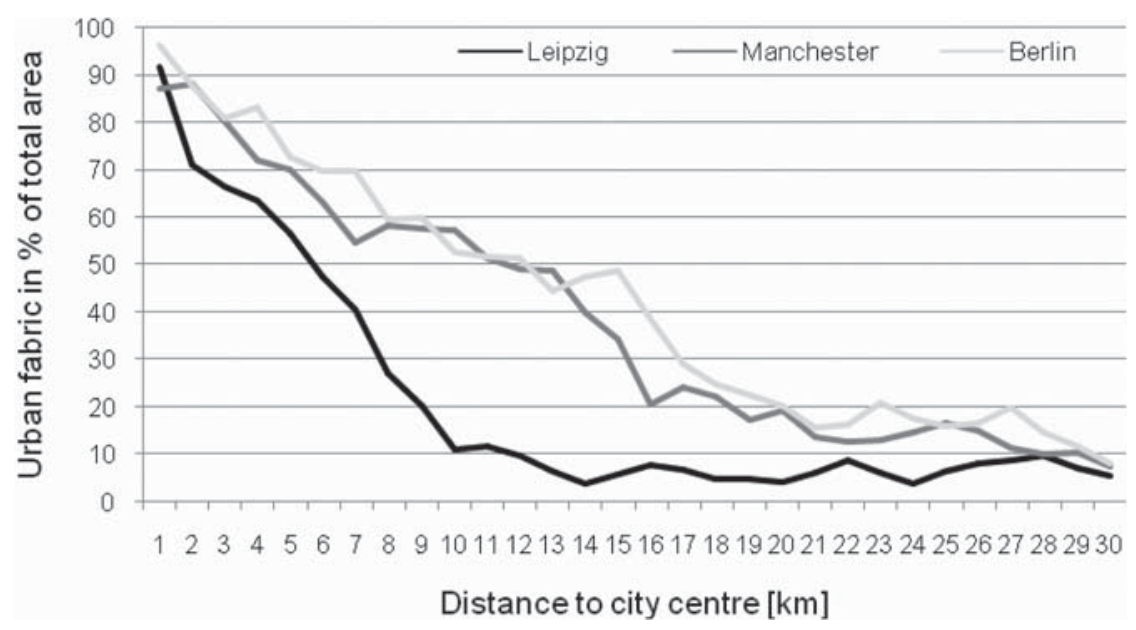

Figure 2: Rural-urban gradients of the land cover class 'urban fabric' for the cities of Berlin, Leipzig and Manchester in year 2000. See Table 2 for data sources.

population density [40] and the greenhouse gas emissions are lower in higher-density development [18]. Energy consumption for the heating and cooling of buildings, which has a share of $48 \%$ of the total global energy consumption [18], is directly correlated to the dwelling area per person [41]. Thus, a lower dwelling area per person in urban centers compared to suburban and rural hinterlands constitutes an important argument for urban resource efficiency. Figure 3 shows an example of rural-urban gradients of dwelling area per person for the cities of Manchester and Hamburg. It can be seen that the dwelling area increases with the distance from the city center. Only the inner city center constitutes an exception to this general trend. A reason for that might be small household sizes and the concentration of rather high-income households in the inner city centers of both cities.

Also the land consumption per person increases with distance from the city center, which is illustrated in form of a rural-urban gradient of sealed surface per person for the city of Munich in Fig. 4.

Not only can the resource consumption as an indicator for the environmental effectiveness be linked to urbanization, but also the economic effectiveness can be related to urbanization. We do this at the national spatial scale by conducting a correlation analysis with data from 182 nations. As an indicator for the economic effectiveness, we use the GDP per person. Obviously, the economic effectiveness seems to rise with increasing urbanization, which can be seen from the result of the correlation between the two variables urbanization rate in \% and GDP per person in US\$, which is shown in Fig. 5. It reveals a logarithmic relationship between both variables with a Pearson's correlation coefficient $r=0.67(p<0.01)$ and $r^{2}=0.51$. Although the variation of the urbanization rate in nations with a low GDP is rather high, all nations with a high GDP per person also show an aboveaverage urbanization rate.

The third basic orientor is called freedom of action. It claims that the system "must have the ability to cope in various ways with the challenges posed by environmental variety" ([9], p. 341). Therefore, the system's agents strive for the maximization of their freedom of choice which is, obviously, higher in urban regions. Here, the diversity and variety of schools, doctors, hospitals, shops, jobs, cultural events, and social contacts etc. is increased due to the higher demand and accessibility compared to rural areas. That facilitates the adaption to different life stages and demands for the 


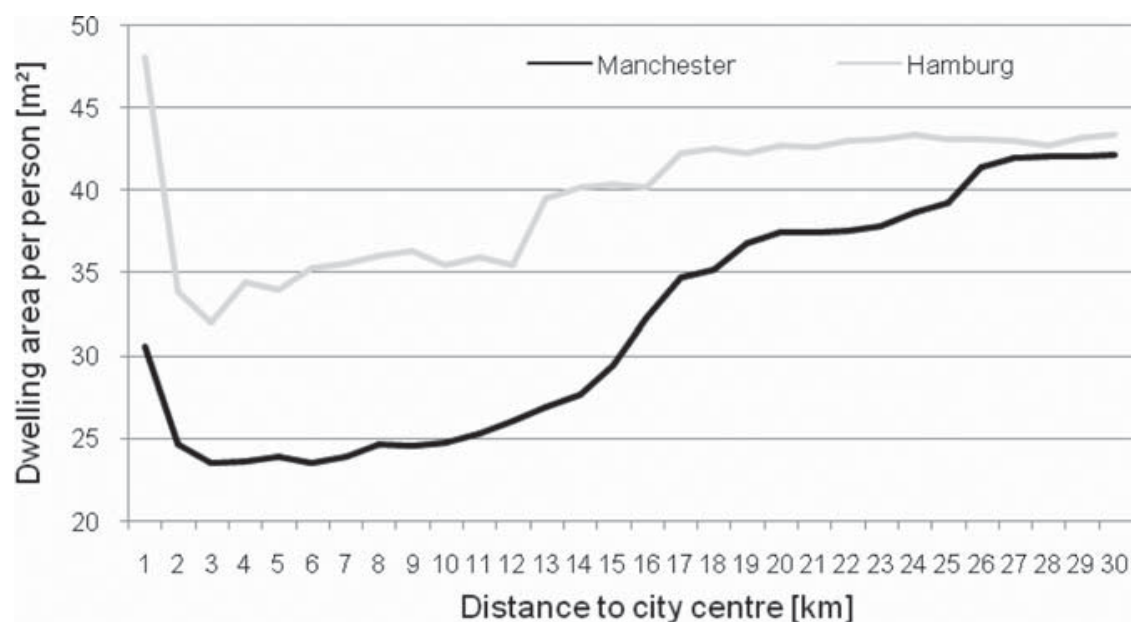

Figure 3: Rural-urban gradient of dwelling area per person for the cities of Manchester (2001) and Hamburg (2005). See Table 2 for data sources.

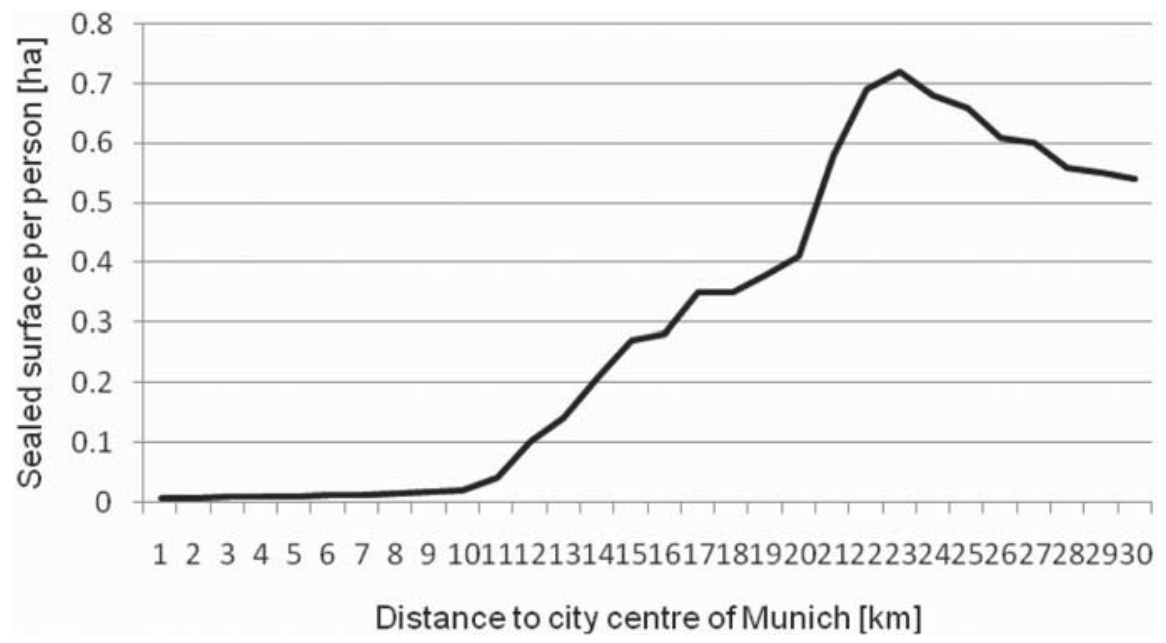

Figure 4: Rural-urban gradient of sealed surface per person for the city of Munich, year 2008. See Table 2 for data sources.

urban population. Figures 6 and 7 show examples of hospital beds per person and foreigners in percentage of the total population in form of rural-urban gradients. Although both gradients show a general decreasing trend from the center to the rural outskirts, the inner city center depicts an exception regarding the density of hospital beds per person. Again, we assume that the high competition with other land uses in the inner city center hinders the construction of hospitals in there.

The freedom of action can also be represented by the availability of internet access, as the internet offers a multitude of possibilities to communicate, consume, work, study, etc. Figure 8 shows a 


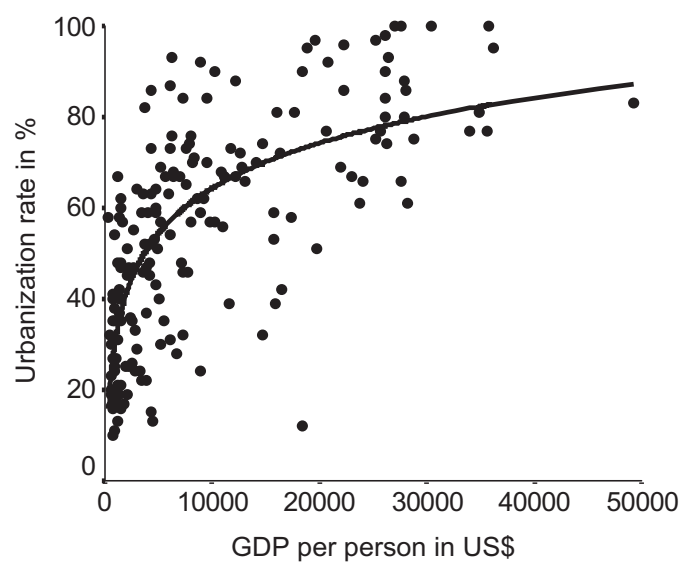

Figure 5: Scatter plot of urbanization rate and GDP per person for $\mathrm{n}=182$ nations. GDP per person shows a high correlation with the urbanization rate $(r=0.67, \mathrm{p}<0.01)$ and a logarithmic relationship between both with $\mathrm{r}^{2}=0.51$. See Table 2 for data sources.

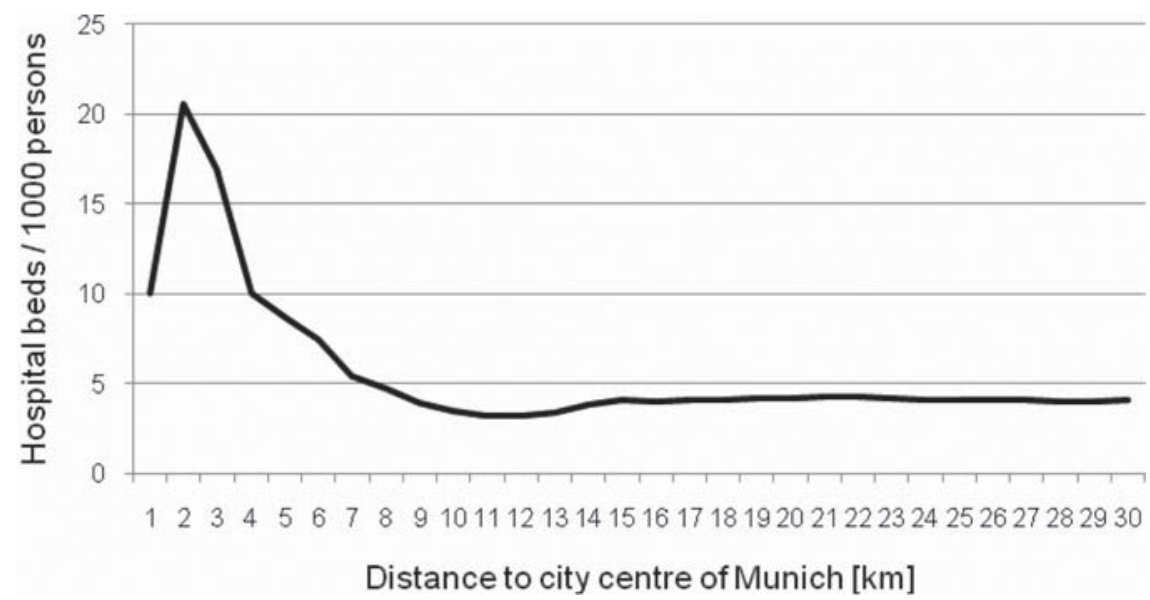

Figure 6: Rural-urban gradient of hospital beds per 1000 persons for the city of Munich, year 2008. See Table 2 for data sources.

scatter plot that demonstrates the relation between urbanization rate and internet users in percentage of the population. The relation can be described with a logarithmic regression curve with $\mathrm{r}^{2}=0.44$, the Pearson's correlation coefficient is $r=0.62(p<0.01)$. Obviously, it is much easier for the urban population to get access to the internet than it is for the rural population.

The security orientor describes the necessity for the system "to be able to protect itself from the detrimental effect of environmental variability" ([9], p. 341). For the human agents of the system, this can mean security from enemies, illness, natural disasters, resource scarcity, economic impoverishment, or social isolation. In former times, one important argument for living in cities was the security from enemies that was ensured by massive city walls or hilltop locations. Mumford [23] states that physical security and social continuity were two big advantages of cities. Portugali [14] 


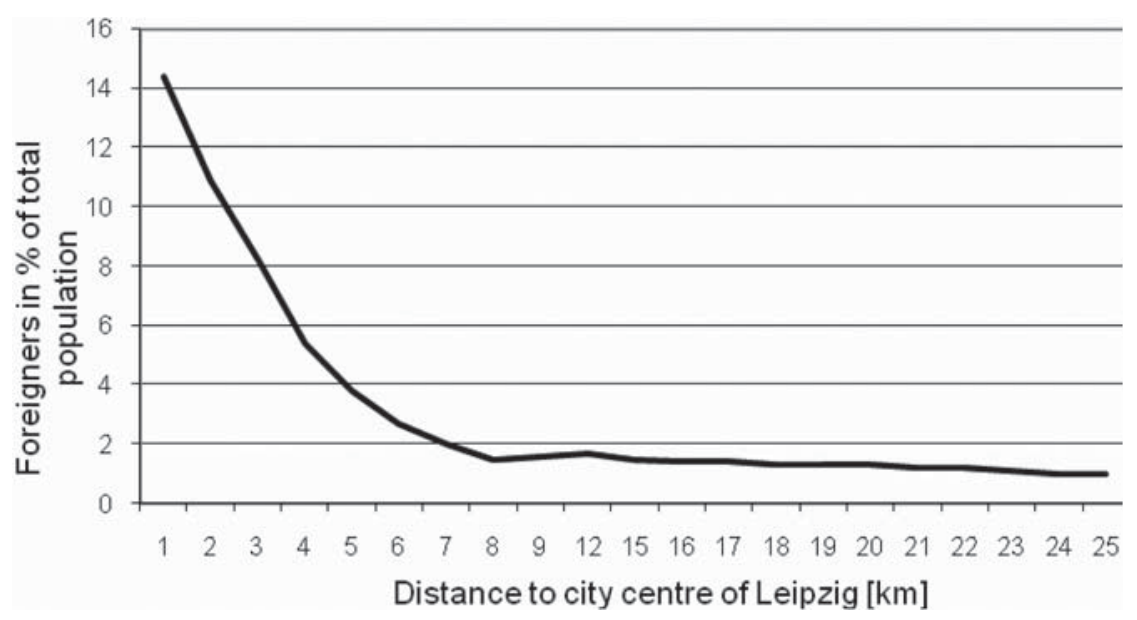

Figure 7: Rural-urban gradients of foreign persons in $\%$ of the total population for the city of Leipzig, year 2005. See Table 2 for data sources.

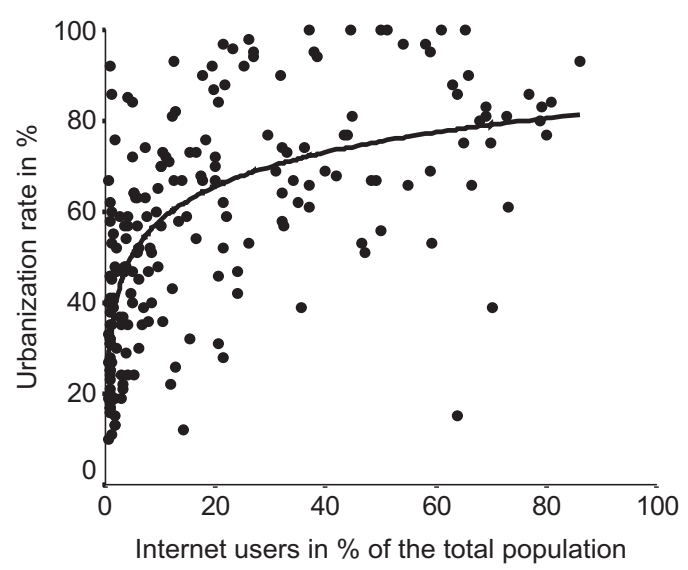

Figure 8: Scatter plot of urbanization rate and internet users in $\%$ of the total population for $n=193$ nations. The percentage of internet users shows a high correlation with the urbanization rate $(r=0.62, p<0.01)$ and a logarithmic relationship between both with $r^{2}=0.44$. See Table 2 for data sources.

adds the internal stability of city systems that leads to reductions of socio-spatial environmental crises. Today, especially the economic security is an important argument for living in cities. The offer of jobs is usually higher and more diverse which is shown in an example for the city of Leipzig (Fig. 9). However, the gradient of employees shows a second maximum in the suburban region, where many new industrial and commercial areas settled recently [32]. This might be an indication for decentralization tendencies of employment in the city of Leipzig.

The cities of Warsaw and Leipzig are examples for lower unemployment rates in the urban center compared to rural surroundings (Fig. 10). However, some districts near the center of Leipzig with mainly large housing estates from the socialist time are structurally rather weak and have high 


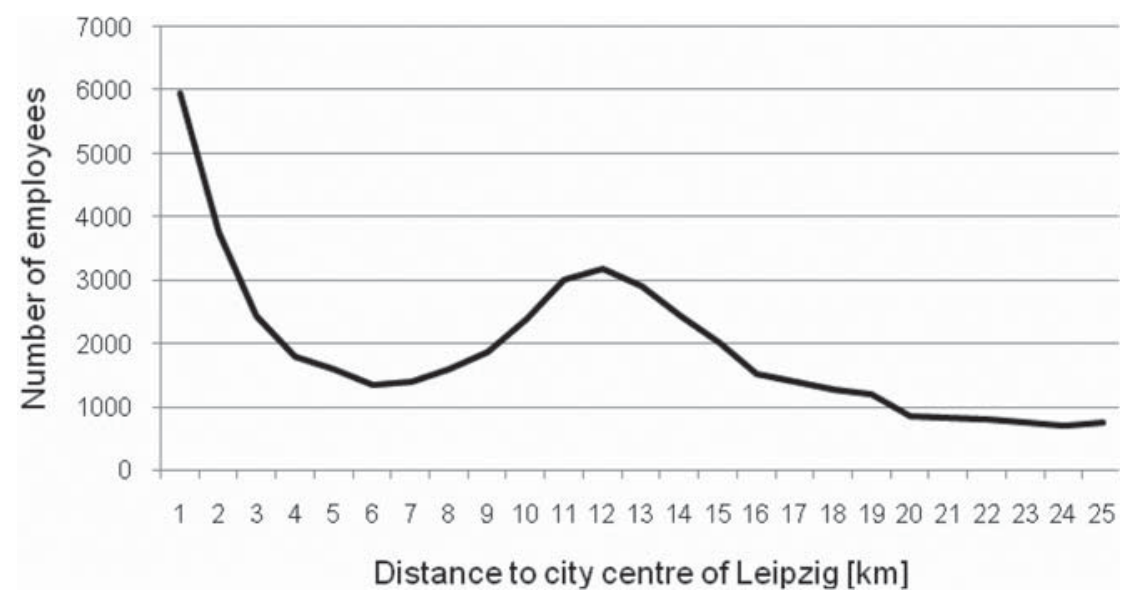

Figure 9: Rural-urban gradient of the number of employees for the city of Leipzig, year 2005.

See Table 2 for data sources.

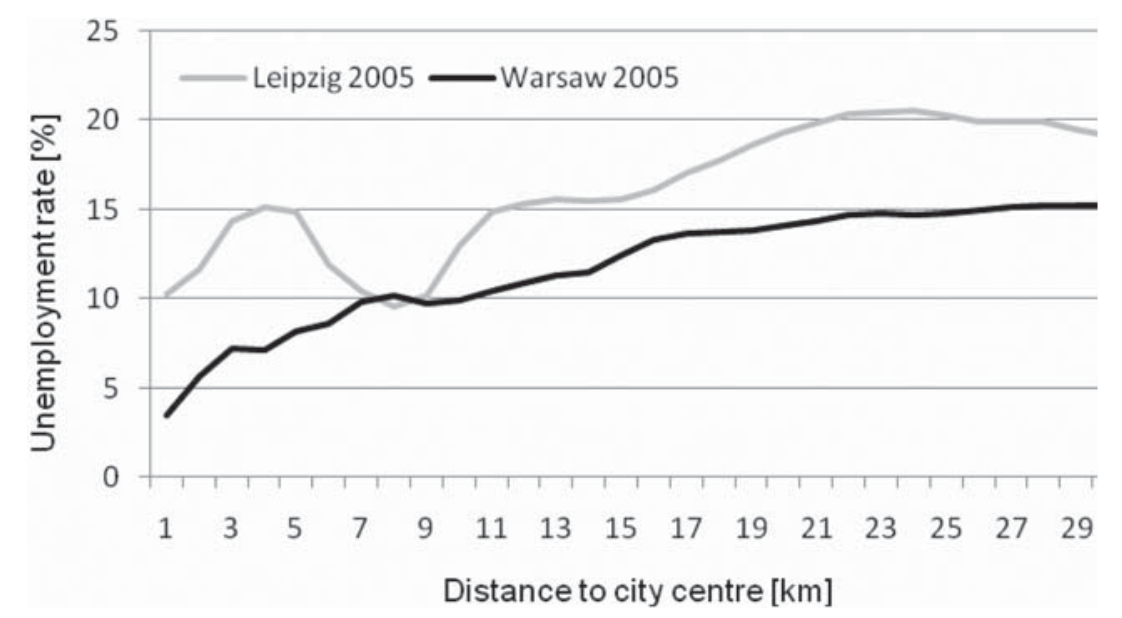

Figure 10: Rural-urban gradient of the unemployment rate for the cities of Warsaw and Leipzig, year 2005. See Table 2 for data sources.

unemployment rates which is the reason for the nonlinear unemployment gradient curve shape of Leipzig. At the scale of nations, the income per person is used here as an indicator for economic security. It correlates with the urbanization rate in \% with a Pearson's correlation coefficient of $r=0.64$ $(\mathrm{p}<0.01)$ and $\mathrm{r}^{2}=0.49$ (logarithmic regression) (Fig. 11). Also the social and health security seems to be higher with an increasing urbanization rate, which is demonstrated by Fig. 12. The Figure shows the correlation between urbanization rate, life expectancy, and the human development index, respectively.

The human development index contains three dimensions: health level, educational level, and living standard.

The adaptability orientor stands for the system's need to "learn, adapt, and self-organize in order to generate more appropriate responses to challenges posed by environmental change" ([9], p. 342). This request is better met in cities, as urban regions offer more possibilities for education, information 


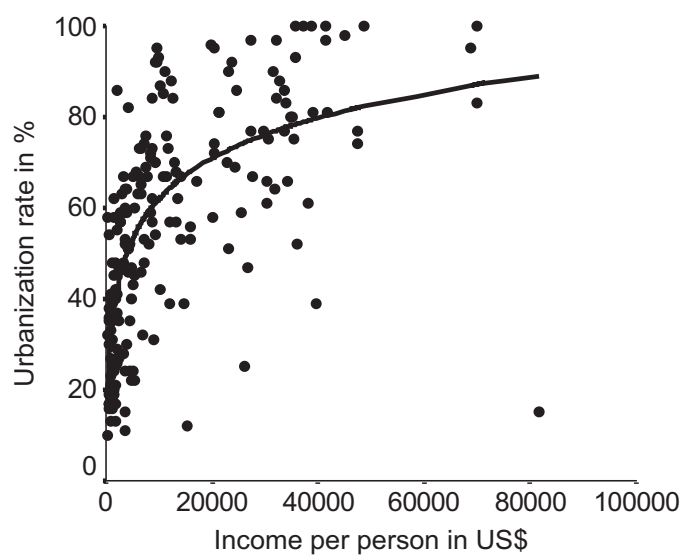

Figure 11: Scatter plot of urbanization rate and income per person for $\mathrm{n}=202$ nations. The income per person shows a high correlation with the urbanization rate $(r=0.64, p<0.01)$ and a logarithmic relationship between both with $\mathrm{r}^{2}=0.49$. See Table 2 for data sources.
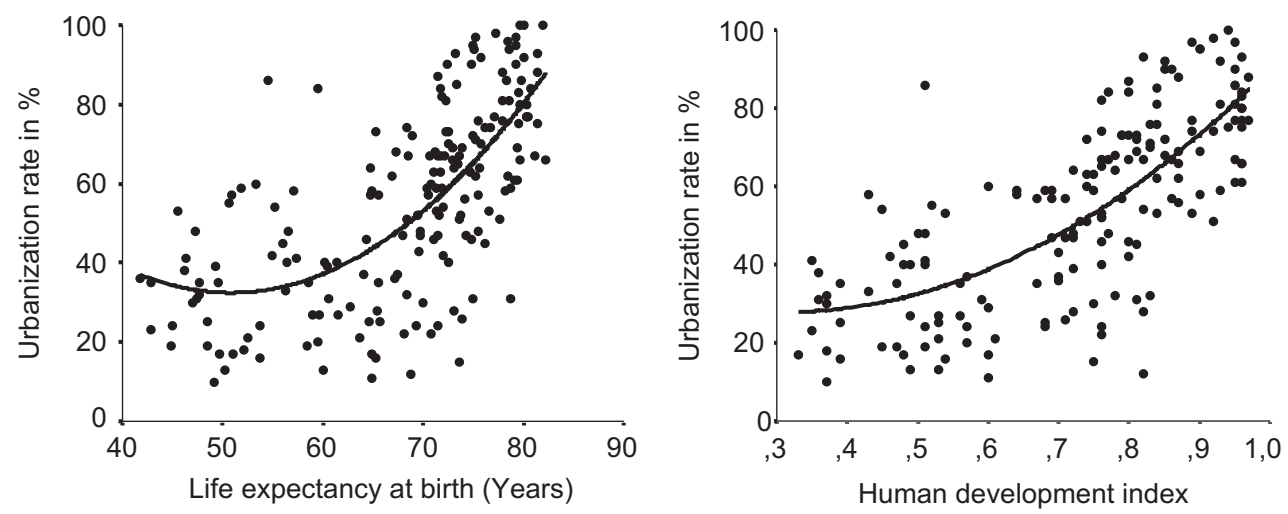

Figure 12: Relationship between urbanization rate and life expectancy at birth (left) with $\mathrm{n}=191$ nations, $r=0.64(p<0.01)$ and $r^{2}=0.47$ and between urbanization rate and the human development index (right) with $\mathrm{n}=176$ nations, $\mathrm{r}^{2}=0.54$. See Table 2 for data sources.

gathering, and adapting to different life stages. Also, the urban population in Europe is usually younger than the rural one, which can be linked to a higher innovation potential. Newman et al. [18] believe that cities are sources of great leadership and innovation and therefore have more capacities to start important initiatives when dealing with global change in comparison to whole nations. Our gradient example for the representation of the adaptability orientor shows the medium age of the city regions of Manchester and Berlin (Fig. 13). The medium age in both cities is lower than in the rural surroundings which assumedly can be linked to a higher flexibility and innovation potential there. Also, at the national level, a high correlation can be found between urbanization rate and the educational level of the population, which increases the capacity for adaptation after an external disturbance of the system. We use the indicators, literacy rate and personal computer users, for the representation of the educational level. Both are highly correlated to the urbanization rate (Fig. 14). 


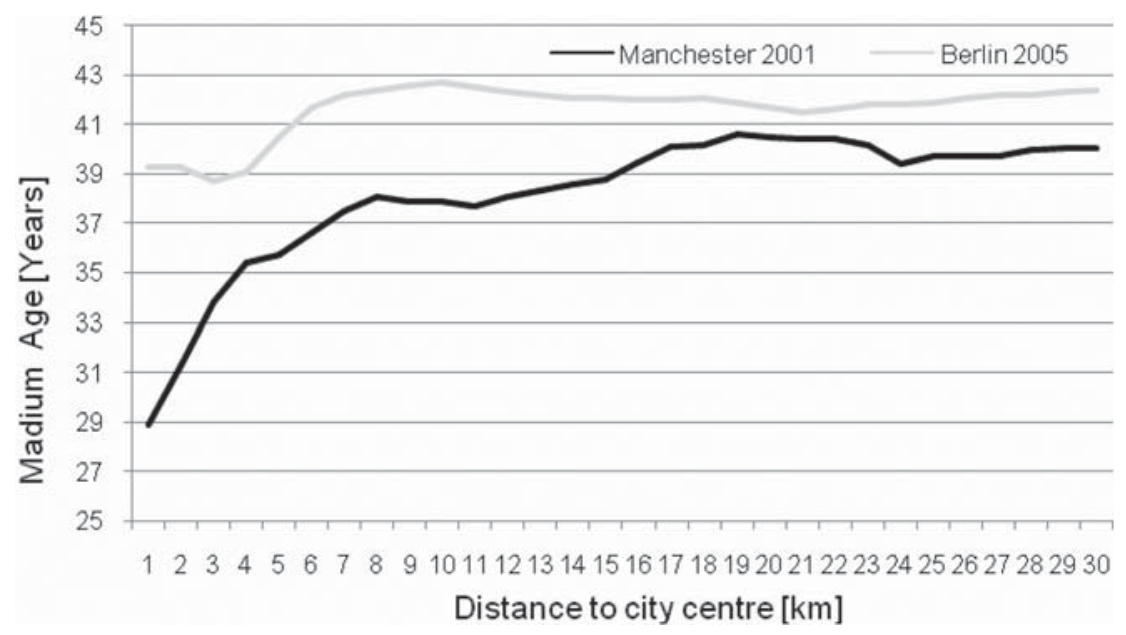

Figure 13: Rural-urban gradient of medium age for the cities of Manchester (2001) and Berlin (2005). See Table 2 for data sources.
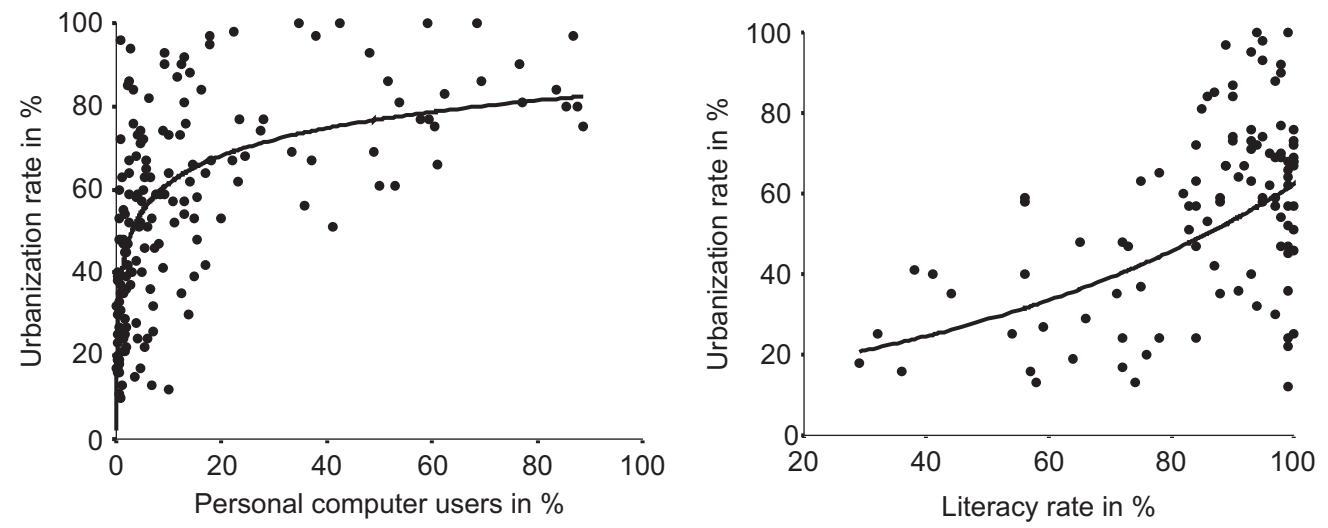

Figure 14: Relationship between urbanization rate and personal computer users (left) with $\mathrm{n}=170$ nations, $r=0.56$ and $r^{2}=0.43$ and between urbanization rate and the literacy rate (right) with $\mathrm{n}=106$ nations, $\mathrm{r}=0.51, \mathrm{r}^{2}=0.27$. See Table 2 for data sources.

The last basic orientor is the coexistence orientor that guarantees the system's behavior in accordance to the interests of other systems in its environment [9]. If interpreted for an urban system, this orientor could describe the aspiration of a beneficial and peaceful coexistence and task sharing with rural regions and other urban regions in the time of globalization. Rural areas have different functions than urban areas and need to offer an adequate supply of resources, food, energy, and water to satisfy the respective urban demand. Urban regions offer money, services, administration, and governance to the rural areas in return. Today, this traditional task sharing often seems to be imbalanced. Gutman [42] argues that not the migration of people, but the migration of wealth from rural to urban regions during the last 200 years was the most dramatic rural-to-urban change resulting in a large gap of rural and urban living standards. Therefore, he asks for a new rural-urban compact that 
involves payment for rural ecosystem services, and not just payment for rural products that are worth less and less on the global markets.

Our example of a rural-urban gradient for the coexistence orientor shows the supply and demand of food in the urban region of Leipzig [32]. It demonstrates the expected fact that the food demand is highest in the urban center, whereas the food supply increases with distance from the center. Although it is clear that food trading plays an important role in the region, the rural hinterland of Leipzig could easily supply enough food to satisfy the demand of the urban population in terms of the food's caloric value (Fig. 15).

\section{DISCUSSION}

Our findings demonstrate that various gradients exist within the rural-urban system. Due to exergy inputs, structural, temporal, and functional rural-urban gradients are built. These gradients provoke disequilibria and potentials for flows, such as commuters, imports, exports, or tourists. The gradients also reveal that some of the basic orientors that represent the system agents' fundamental interests in self-organizing systems [9] are better met in urban regions. Thus, the basic orientors can help explaining the existence of cities. However, although all basic orientors have to be considered, the preferences of the system agents change in time and space. In former times, the security orientor was one of the main arguments to build and live in cities which offered effective fortification and security against enemies. Today, this purpose of cities has lost its relevance and the trade-off between freedom and security plays an important role in public discussions. The shift in the weighting of basic orientors, but also major processes such as the globalization and digitization has impacts on temporal changes of rural-urban gradients. Against the background of the rise of new information technologies and a shift of social and economic activities into the virtual world of the internet, Läpple [43] discusses the decreasing importance of the bodily presence and an easing of traditional locational ties that until now hold large urban agglomerations together. In this vein, it is not unlikely that an enhanced use of the internet increases tendencies of decentralization and thus has the potential to change the appearance of the described rural-urban gradients.

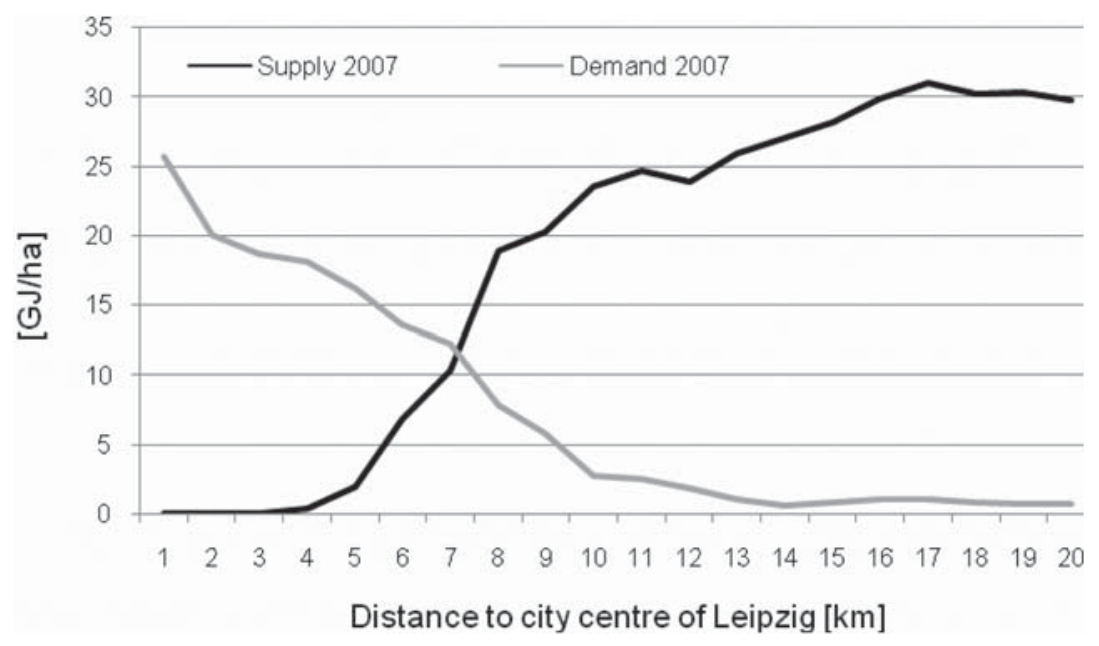

Figure 15: Rural-urban gradients of the demand and supply of food in GJ/ha for the city region of Leipzig, year 2007, after Kroll et al. [32]. 
Self-organized system behavior according to basic orientors and the consequential tendency of the human population to concentrate in urban agglomerations suggest that the final result of this development will be a world in which the whole global population is living in urban areas. However, reality proves that urbanization is not a continuous process but rather develops in a cyclical manner that includes phases of urbanization, suburbanization, deurbanization, and reurbanization [44]. In past and present times, there have always been a considerable number of cities that have been shrinking; parallel to others which have been growing. There are many causes of destruction or shrinkage of cities, as for example wars, natural disasters, water scarcity, epidemics, economic transformations, or political transformations [45]. In all cases, the affected city was not able to cope with or recover from the external disturbance that impacted on the urban system. Holling [46] described this breakdown following a major external disturbance, which he called creative destruction, as one phase of an adaptive cycle of ecosystems. As causes for the reduced adaptability and a consequential breakdown, he names the high connectivity and mutual dependency of the system. Tainter [47] has adopted this concept to the evolution of human societies. He explains the increasing complexity of human societies with the competitive advantage and problem-solving capacity of complexity. However, the increase of the complexity of a system requires continuous energy input into the system along a flattening benefit-cost curve. At the point when the return of continued investments in complexity is declining, the society becomes vulnerable to destruction [47].

Although we found a correlation between the urbanization rate and economic and social indicators representing orientor development, this relation might not be true for specific urban regions. Especially megacities in developing countries are often facing increasing poverty, conflicts, sociospatial and political-institutional fragmentation and are more vulnerable to environmental and anthropogenic disturbances than smaller urban areas [27]. In most cases, the rapid population development of such megacities is decoupled from their economic development, happens without a parallel increase of agricultural production and is not accompanied by adequate investments into infrastructure, education, and public health care [26]. According to the theories of Holling and Tainter, the fast increasing complexity of megacities in developing countries that is not accompanied by an enhanced exergy input will eventually lead to collapse. Also the rural-urban gradients would look much different for such huge cities in developing countries in comparison to smaller European cities. This is due to a frequently observable development of polycentric urban conglomerates along communication axes that blurs the borders between urban and rural areas [26].

Thus, ongoing urbanization is not necessarily a 'good thing', especially when it comes along with uncontrolled urban sprawl and insufficient investments into the maintenance of the urban system.

On the other hand, not only city regions in the developed world, but also megacities in developing countries are considered as having potential innovative milieux due to the available human resources and globally linked actors [27]. All cities have the potential to enhance sustainability by efficient resource use and therefore provide the great opportunity to reduce carbon dioxide emissions due to their high-density development and potential for public transport [18]. Thus, it can be said that cities "present both the problems and solutions to sustainability challenges of an increasingly urbanised world" ([48], p. 756).

\section{CONCLUSIONS}

In this study we have tried to link several theoretical concepts and apply them to the 'real-world problem' of urbanization. The basic orientors are comprehended as emergent properties of open systems. They are the outcomes of self-organized processes and in the context of ecosystem theories they can be used to describe the functionality and resilience of environmental systems. In this article we have applied the orientor approach to socioeconomic systems. It could be found that the approach 
provides a suitable methodology to describe the sustainability of rural-urban systems and to reflect the utility of emergent properties for the existence of the investigated entities.

Using gradients as indicators for the resulting (self-organized) spatial patterns it could be shown that long-term development of human landscapes also leads to regular parameter distributions which can be understood as optimized states of orientor dynamics. As such the gradient patterns contribute to human well-being in an optimized manner as long as their internal and external connectivity does not succeed regional threshold values.

From a methodological viewpoint the investigation has furthermore shown that the gradient approach is a suitable instrument to depict and understand the structural differences between agglomerations and their environment. Taking into account thermodynamic arguments, the mapped gradients also provide enormous potentials for flows: water, energy, materials, food, labour force, and many other items consequently are transferred into the urban systems, whereas money, information, waste, and several cultural issues are the main products that are transferred into the hinterland. In parallel to ecosystems, these flows provide the basic conditions for the existence of the created rural-urban structures. Consequently, the dynamics of the rural-urban concentration profiles can also be used as information sources for the sustainability of the overall system: how much exergy is used to keep the urban agglomeration vital? And how much entropy is produced in the cities to be exported into their environments? Both variables are related to the complexity, to the related connectivity and to the linked costs and demands for maintenance of the whole system.

In general, it is possible to show higher performances of variables that represent Bossel's basic orientors (e.g. indicators for resource efficiency, economic performance, and social infrastructure) in European urban regions in comparison to their rural counterparts. Also at the global level, using data at the national scale, the urbanization rate is positively correlated to many social and economic indicators that can be linked to the basic orientors. But urbanization is not a linear process, as human systems show a varying adaptability and resilience and have to cope with external disturbances that can lead to destruction. And if we look at some mega cities, the mentioned optimal complexity may have passed the threshold values in some cases, thus the whole system becomes inefficient and brittle. Furthermore, it has to be kept in mind that the gradients which provide the mentioned exergetic flows demonstrate extreme dependencies of the cities from the conditions in their hinterlands.

Returning to the initial questions asked in the introduction, the following assumptions can be stated:

- The basic orientors can be utilized to explain the existence of cities and ongoing urbanization. Several orientor interests are better met in cities, if the relations with the rural surroundings are balanced. As long as this balance can be fulfilled, urbanization may keep on increasing, better not striving for a maximization but an optimization under the prevailing conditions.

- The presented results demonstrate that orientor approaches are not only restricted to ecological systems and that self-organization processes can also be found and investigated in human systems. Therefore, there is still a positive potential of concept application and case comparison, if respectively aggregated indicator sets are developed which demonstrate the sustainability of urban or urban-rural systems as a set of basic orientors.

- Also the gradient principle can be applied to human systems without any problems. Any structure which has been created depicts a structural or functional gradient. Further methodological development should connect the prevailing gradients with the interrelated flows and resistances. But concerning this task, several indirect and de-localized effects have to be taken into account, i.e. because today the flows are extremely influenced by globalized trade relations. Thus, the old regional interactions have been substituted by relationships on broad spatial scales. 
- Human systems can be investigated and understood as self-organized systems. They fulfil all criteria and conditions of self-organization (see Table 2 in Müller and Kroll [1]) from a physical viewpoint. Restrictions concerning the 'self' - the concentration on internal regulations as developmental drivers of human systems - may be discussed on the base of theological attitudes, but these arguments are not considered here.

Therefore, the combination of gradients and basic orientors can be used to describe the existence and development of cities. Bossel's orientors may be even more suitable instruments to support sustainable development in socioeconomic entities than in (non-teleological) ecological systems because humans should be much better able to adapt to potential deficits and follow orientor optimizations in a conscious, regulated, and target-related, rational manner.

\section{ACKNOWLEDGMENTS}

This work was financially supported by the EU Integrated Project PLUREL (contract no. 036921).

\section{REFERENCES}

[1] Müller, F. \& Kroll, F., Integrating ecosystem theories - gradients and orientors as outcomes of self-organized processes. International Journal of Design \& Nature and Ecodynamics, 6(X), pp. 000-000, (in print), 2011.

[2] Müller, F. \& Fath, B., The physical basis of ecological goal functions - an integrative discussion. Eco Targets, Goal Functions and Orientors, eds F. Müller \& M. Leupelt, Springer: Berlin, pp. 269-285, 1998.

[3] Nicolis, G. \& Prigogine, I., Self-Organisation In Nonequlibrium Systems: From Dissipative Structures To Order Through Fluctuations, Wiley-Interscience: New York, p.4, 1977.

[4] Prigogine, I., From Being To Becoming: Time and Complexity in the Physical Sciences, Freeman: San Francisco, 1980.

[5] Odum, H.T., Self-Organisation, Transformity and Information. Science, 242(4882), pp. 1132-1139, 1988. doi:http://dx.doi.org/10.1126/science.242.4882.1132

[6] Prigogine, I., The End of Certainty: Time, Chaos and the New Laws of Nature. Free Press: New York, 1997.

[7] Joergensen, S.E., B. Fath, S. Bastianoni, Marquez, J., Müller, F., Nielsen, S.N.,Patten, B., Tiezzi, E. \& Ulanowicz, R., A New Ecology - The Systems Perspective. Elsevier Publishers: Amsterdam, 2007.

[8] Pulselli, R. \& Tiezzi, E., City Out Of Chaos, WIT Press: Southampton, 2010.

[9] Bossel, H., Policy assessment and simulation of actor orientation for sustainable development. Ecological Economics, 34(X), pp.337-355, 2000. doi:http://dx.doi.org/10.1016/S0921$\underline{8009(00) 00218-4}$

[10] Müller, F. \& Leupelt, M., Eco Targets, Goal Functions, and Orientors. Springer-Verlag: Berlin, 1998.

[11] Holling, C.S., Understanding the Complexity of Economic, Ecological, and Social Systems. Ecosystems, 4(X), pp. 390-405, 2001. doi:http://dx.doi.org/10.1007/s10021-001-0101-5

[12] Müller, F., Gradients in ecological systems. Ecological Modelling, 108, pp. 3-21, 1998. doi:http://dx.doi.org/10.1016/S0304-3800(98)00015-5

[13] Allen, P. \& Sanglier, M., Urban evolution, self-organisation and decision making. Environment and Planning A, 13, pp. 169-183, 1981. doi:http://dx.doi.org/10.1068/a130167

[14] Portugali, J., Self-organizing cities. Futures, 29(4/5), pp. 353-380, 1997. doi:http://dx.doi. org/10.1016/S0016-3287(97)00022-0 
[15] Küppers, G., Der umgang mit unsicherheit: zur selbstorganisation sozialer systeme. Komplexe Systeme und nichtlineare Dynamik in Natur und Gesellschaft. Komplexitätsforschung in Deutschland auf dem Weg ins nächste Jahrhundert, ed. K. Mainzer, Springer: Berlin, pp. 348-372, 1999.

[16] Portugali, J., Self-organisation and the City, Springer: Heidelberg, 2000.

[17] Imada, T., Self-organisation and Society, Springer: Tokyo, 2008.

[18] Newman, P., Beatley, T. \& Boyer, H., Resilient cities, Responding to Peak Oil and Climate Change, Island Press: Washington, 2009.

[19] Bossel, H., Deriving indicators of sustainable development. Environmental Modeling and Assessment, 1, pp. 193-218, 1996. doi:http://dx.doi.org/10.1007/BF01872150

[20] Bossel, H., Ecological orientors: emergence of basic orientors in evolutionary self-organization. Eco targets, goal functions and orientors, eds F. Müller \& M. Leupelt, Springer, Berlin. pp. 19-33, 1998.

[21] Pumain, D. An evolutionary approach to settlement systems. New forms of urbanisation: beyond the rural-urban dichotomy, eds T. Champion, H. Graeme, Ashgate Publishing: Aldershot.

[22] Portugali, J., Notions concerning the nature of world urbanisation. Progress in Planning, 46(3), pp. 145-162, 1996. doi:http://dx.doi.org/10.1016/0305-9006(96)88867-2

[23] Mumford, L., The Natural History of Urbanisation, In: Thomas W.L. (Eds.) Man's Role in the Changing the Face of the Earth. University of Chicago Press, Chicago, 1956.

[24] Marti-Henneberg, J., Empirical evidence of regional population concentration in Europe, 18702000. Population Space and Place, 11(4), pp. 269-281, 2005. doi:http://dx.doi.org/10.1002/ psp. 373

[25] UNPD, World Urbanisation Prospects: The 2005 Revision, United Nations Population Division: New York, 2005.

[26] Davis, M., Planet of Slums, Verso: London, 2006.

[27] Kraas, F., Megacities and global change: key priorities. Geographical Journal, 173(1) pp. 79-82, 2007.

[28] Cowgill, G.L., Origins and development of urbanism: archaeological perspectives. Annu. Rev. Anthropol,33, pp. 525-49, 2004. doi:http://dx.doi.org/10.1146/annurev.anthro.32.061002.093248

[29] Lösch, A., The Economics of Location, Yale University Press: New Haven, CN, 1954.

[30] Christaller, W., Central Places in Southern Germany, Prentice Hall: Englewood, Cliffs, NJ, 1966.

[31] Kroll, F. \& Kabisch, N., The relation of diverging urban growth processes and demographic change along an rural-urban gradient. Population Space and Place, 2011. doi:http://dx.doi. org/10.1002/psp.653

[32] Kroll, F., Müller, F., Haase, D. \& Fohrer, N., Rural-urban gradient analysis of ecosystem services supply and demand dynamics. Land Use Policy, 2011. doi:http://dx.doi.org/10.1016/ j.landusepol.2011.07.008

[33] German Federal Statistical Office, Statistik lokal 2007, Daten für die Kreise, Kreisfreien Städte und Gemeinden Deutschlands, DVD, 2007.

[34] Statistical Office Leipzig, Ortsteilkatalog 2006. Stadt Leipzig, Amt für Statistik und Wahlen, Leipzig, 2006.

[35] German Federal Environment Agency, DLR, DFD, CORINE Land Cover 2000. Daten zur Bodenbedeckung Deutschland, DVD, 2004.

[36] World Bank, World Development Indicators Online 2008. Available online: http://go.worldbank. org/U0FSM7AQ40, 2008.

[37] Heston, A., Summers, R. \& Aten, B., Penn World Table Version 6.2, Centre for International Comparisons of Production, Income and Prices at the University of Pennsylvania, Pennsylvania, 2006. 
[38] Partzsch, D., Zum Begriff der Funktionsgesellschaft. Mitteilungen des Deutschen Verbandes für Wohnungswesen, Städtebau und Raumplanung, number IV, pp. 3-10, 1964.

[39] Weisz, H. \& Steinberger, J.K., Reducing energy and material flows in cities. Current Opinion in Environmental Sustainability, 2, pp. 185-192, 2010. doi:http://dx.doi.org/10.1016/ j.cosust.2010.05.010

[40] Kennedy, C., Duddihy, J. \& Engel-Yan, J., The changing metabolism of cities. Journal of industrial ecology, 11(2), pp. 43-59, 2007. doi:http://dx.doi.org/10.1162/jie.2007.1107

[41] German Federal Statistical Office, Energieverbrauch der privaten Haushalte. Begleitmaterial zur Pressekonferenz 5, Berlin, November 2008.

[42] Gutman, P., Ecosystem services: foundations for a new rural-urban compact. Ecological Economics, 62, pp. 383-387, 2007. doi:http://dx.doi.org/10.1016/j.ecolecon.2007.02.027

[43] Läpple, D., City and region in an age of globalisation and digitization, german. Journal of Urban Studies, 40(2), pp. 1-19, 2001.

[44] van den Berg L., Drewett R., Klaassen L.H., Rossi A. \& Vijverberg C.H.T., Urban Europe: A Study of Growth and Decline. Pergamon Press: Oxford, 1982.

[45] Rienits, T. \& Oswalt, P. (eds), Atlas of Shrinking Cities, Ostfildern: Hatje Cantz Verlag, 2006.

[46] Holling, C.S., The resilience of terrestrial ecosystems: local surprise and global change. Sustainable Development of the Biosphere, eds W.M. Clark \& R.E. Munn, Cambridge University Press, Oxford, pp. 292-320, 1986.

[47] Tainter, J.A., Sustainability of complex societies. Futures, 27(4), pp. 397-407, 1995. doi:http://dx.doi.org/10.1016/0016-3287(95)00016-P

[48] Grimm, N.B, Faeth, S.H., Golubiewski, N.E., Redman C.L., Wu, J., Bai, X. \& Briggs, J.M., Global change and the ecology of cities. Science, 319(5864), pp. 756-760, 2008. doi:http:// dx.doi.org/10.1126/science.1150195

[49] Ulrich, H. \& Probst, G. Self-organisation and management of social systems, Springer: Heidelberg, 1984. doi:http://dx.doi.org/10.1007/978-3-642-69762-3 